\title{
The Ability of Peat in Adsorption of Biogenic Elements from Water Environment
}

\author{
Oksana Matsuska1", Olga Suchorska', Jaroslaw Gumnitsky² \\ 1 Department of Ecology, S. Gzhytskyi National University of Veterinary Medicine and Biotechnologies Lviv, \\ Pekarska Str. 50, Lviv, 79010, Ukraine \\ 2 V. Chornovil Institute of Sustainable Development, Lviv Polytechnic National University, S. Bandera Str. 12, \\ Lviv, 79013, Ukraine \\ * Corresponding author's e-mail: kasanam@meta.ua
}

\section{ABSTRACT}

The possibilities of using a natural sorbent - peat for the wastewater treatment of ammonium ions and phosphates discharged from runoff into natural reservoirs at high concentrations were investigated. The peat of from the Vereshchytsya-Yanovske deposit of Ukraine of two depths: lowland and upland, was studied. It was established that the lowland samples of peat have higher sorption properties to the investigated pollutants from the aquatic environment than the upland ones. A greater moisture loss in the lowland peat species was observed, as well as the major part of the plant fibers in its structure, which explains its sorption properties. Due to the high content of humic substances, the extraction of cations from the water by peat can occur due to the ion exchange. The adsorption isotherms of both ammonium and phosphate ions on the top and lowland peat species of the VereshchytsyaYanovske deposit were constructed and presented. The adsorption isotherm obtained in the experimental studies was used to mathematically establish the isotherm equation, using the Langmuir and Freundlich models to describe the equilibrium of the sorption processes under study. The degree of appropriation of linear equations to the experimental data was evaluated on the basis of the deterministic coefficient, which enabled to determine that in each case the Langmuir equations describe the adsorption isotherms more adequately.
\end{abstract}

Keywords: wastewater, ammonium nitrogen, phosphates, adsorption, peat, adsorption isotherms, coefficient of determination, Langmuir and Freundlich models.

\section{INTRODUCTION}

The problem of environmental pollution by wastewater of different industries remains urgent. The entry of the untreated and insufficiently treated wastewater of the chemical industry, household sector, agriculture, both in surface water and wastewater, creates a number of problems of ecological and economic character [Boroday 2014, Sabadash 2016].

The wastewater of the agro-industrial complex (AIC) are complex multicomponent systems, containing the pollutants of both mineral and organic origin, which require the search for the effective methods of their purification [Kushvaha 2011, Krasinko 2012]. The results of the environmental assessment of the wastewater of the meat processing enterprises indicate an exceedance of the maximum permissible limit (MPL) for ammonia nitrogen content - 1.3-3 MPL, phosphate - 2.4-3 MPC. The concentration of ammonium nitrogen and phosphate in poultry farms is 3.8 MPL and $~ 10$ MPL, respectively. In the wastewater of dairy enterprises - the content of ammonia nitrogen reaches $2.5 \mathrm{MPL}$, phosphate - 4.3-10 MPL [Matsuska 2010, Sabliy 2013].

Often, biological wastewater treatment is used to clean the agricultural wastewater [Masliy 2015] using special biological systems consisting of bacteria or enzymes capable of destroying organic pollutants under aerobic and anaerobic conditions. This causes the loss of valuable food components. 
In addition, the biological treatment of highly concentrated liquids requires their prior preparation with the mechanical and physicochemical methods and is ineffective for the extraction of biogenic elements, especially nitrogen compounds, from effluents. This method is most appropriate for the removal of dissolved organic matter, but is not advantageous for low-power plants, because it requires high costs for its implementation and operation.

The use of the physicochemical methods is the most optimal in this case. These include membrane filtration, flotation, reagent treatment and adsorption [Ye 2012; Stepa 2014; Scharma 2014]. The most common of these methods are coagulation and flocculation, which allow for the single intake of organic and inorganic coagulants to precipitate the major contaminating components, thereby facilitating their removal during further settling or filtration. The disadvantages of flocculation and coagulation are a small degree of purification $(\sim$ $90 \%$ ) due to the instability of the process and the secondary contamination of purified water with residues of the reagent. The high cost and scarcity of, for example, the use of cellulose-based ion exchange resins impedes their widespread use in the water purification processes.

The analysis and comparison from the technical and economic point of view of the known methods for the extraction of ammonium nitrogen from aqueous solutions allows stating that the method of adsorption and ion exchange using natural dispersed sorbents is one the most effective [Humnytskyy 2011, Borkowski 2012, Malovanyy 2019].

Purification of aqueous solutions using natural sorbents meets many requirements of the environmentally friendly and energy-efficient production based on the principle of waste [Timchuk 2013, Matsuska 2019]. Abundant geological reserves, cheap rock extraction, easy preparation for transportation and use in cleaning, the ability to use waste sorbents in other technologies are the main advantages of using natural sorbents.

The purpose of this work was to study the adsorption capacity of peat (upland and lowland) Vereshchytsya-Yanovske deposit to the contaminants of agricultural wastewater, namely ammonium nitrogen and phosphates.

\section{MATERIALS AND METODS}

Peat is a polydisperse system based on the vegetable residues of solid polymers of cellulosic nature and their decay products, which are in equilibrium with an aqueous solution of low and high molecular weight substances. The main source of inorganic peat compounds is the water migration of the mineral components coming from the flood and groundwater, as well as the air and biogenic migration. The inorganic part of peat water is represented mainly by cations (mostly $\mathrm{Ca}^{2+}, \mathrm{Mg}^{2+}$, $\left.\mathrm{Fe}^{3+}, \mathrm{Al}^{3+}, \mathrm{K}^{+}, \mathrm{Na}^{+}\right)$and anions $\left(\mathrm{HCO}^{3-}, \mathrm{NO}^{3-}, \mathrm{Cl}^{-}\right.$, $\mathrm{SO}_{4}^{2-}$ ) of chemical elements. The content of cations in the peat water (especially $\mathrm{Ca}^{2+}$ ) affects the acidity of the medium and determines the concentration of dissolved organic compounds.

The source of organic matter of peat is marsh peat-forming plants: mosses, grasses, wood species. The composition and properties of peat depend on the chemical characteristics of the plant material, and therefore on the type of peat. The basis of the organic constituent of peat are the humic substances (humic acids, fulvic acids and their salts), which cause the ionexchange properties of peat.

The ion-exchange properties of the humic substances are due to the large number of carboxyl $-\mathrm{COOH}$ and phenolic $-\mathrm{OH}$ groups. More than $50 \%$ of the ion exchange is in the carboxyl groups, since phenolic hydroxides are practically not dissociated at $\mathrm{pH}<6$ and enter the ion exchange only at $\mathrm{pH}=9-10$ with the formation of spatial structures that are able to absorb and retain a large amount of water with dissolved substances, which emphasizes their adsorption properties [Kravchenko, 2009].

For the studies on the adsorption capacity of peat, its samples were taken from the Vereschytsya-Yanovske deposit of Ukraine from different depths: $10-20 \mathrm{~cm}$ and about $1.5 \mathrm{~m}$. The photos of the peat samples selected for analysis are presented in Figue1 ( $a$ - peat, $b$ - lowland peat).

he origin of peat significantly affects its chemical composition. The humic acid content of the lowland peat samples is about 1.6 times higher than that of the upland peat. The salts in the lowland samples of peat also contains a lot $-200-700$ $\mathrm{mg} / \mathrm{l}$, in the top - up to $70-180 \mathrm{mg} / \mathrm{l}$. The structure of the selected peat samples was observed by under a microscope (Fig. 2).

In the structure of lowland peat samples (Fig. 2b), unlike the upland peat (Fig. 2a), vegetable fibers prevail, which confirms the high content of the organic matter in it.

The moisture loss of the studied peat samples (6 grams of upland and lowland samples) was 
a)

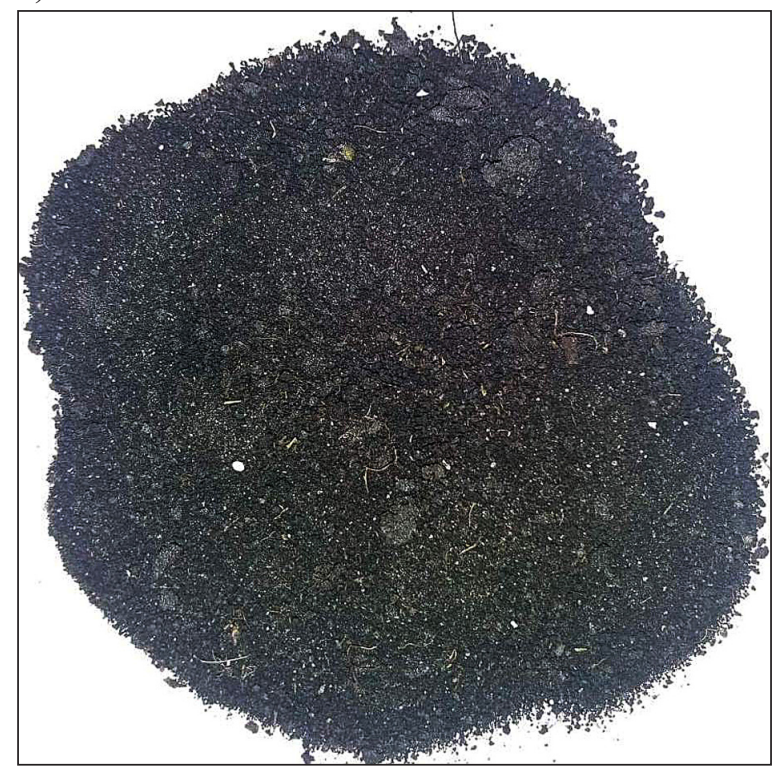

b)

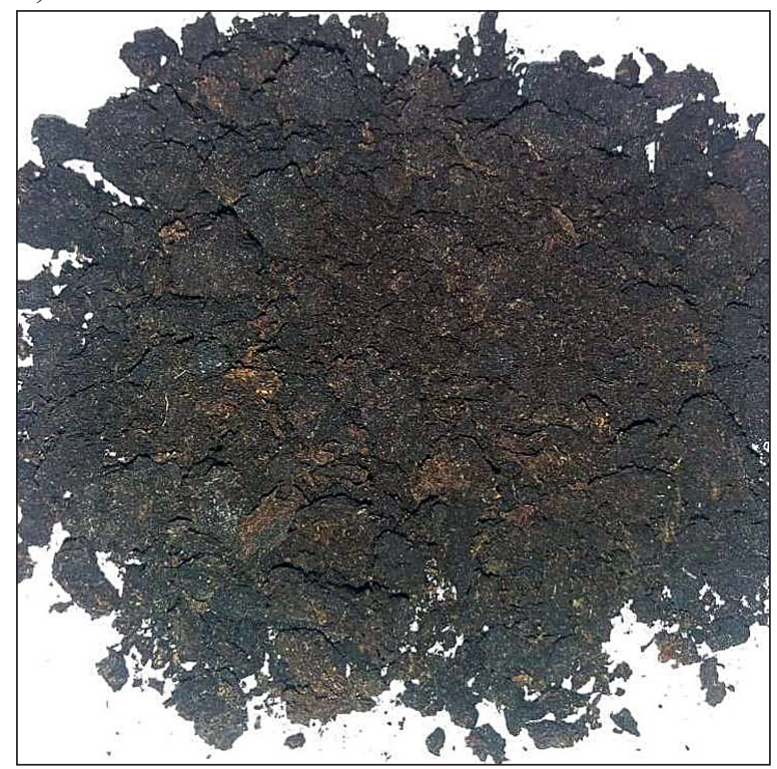

Fig. 1. Photo of the selected samples of the Vereshchytsya-Yanovske peat field: a) upland and b) lowland

a)

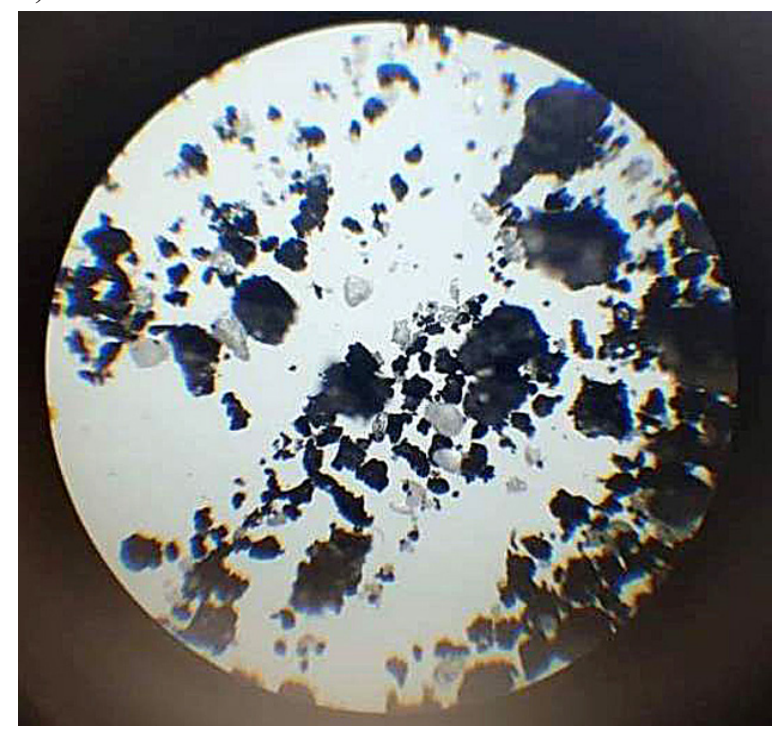

b)

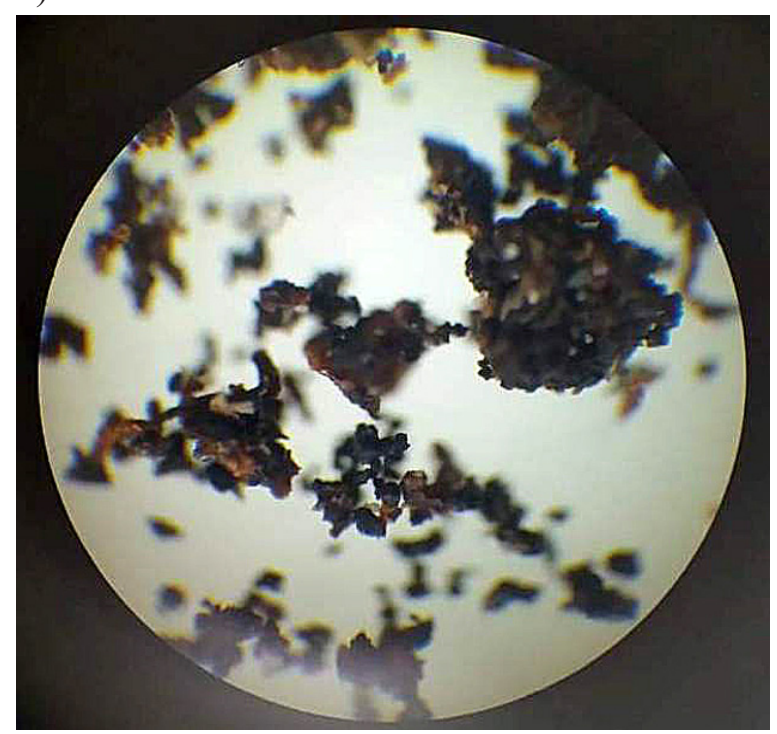

Fig. 2. Photo of the studied samples of the Vereshchytsya-Yanovske peat under a microscope ( $7 \times 8$ magnification): a) upland and b) lowland

carried out by drying them in a drying cabinet, in open aluminum boxes, to a constant mass at $\mathrm{t}-60 \pm 3^{\circ} \mathrm{C}$ for 3 hours.

In order to determine the moisture loss of peat, the following ratio was used:

$$
W=\frac{m_{1}-m_{0}}{m_{1}} 100 \%
$$

where: $m_{1}-$ mass of the moisture peat, $\mathrm{g}$;

$$
m_{0}-\text { mass of the dry peat, } \mathrm{g} \text {. }
$$

The studies on thepeat adsorption capacity were carried out under static conditions with periodic stirring of model solutions of ammonium chloride and potassium monophosphate $\left(100 \mathrm{dm}^{3}\right)$ with pre-dried sorbent samples (low and high approximate mass of 2.7-3.7 g, respectively) for two days at $+(20 \pm 0.5){ }^{\circ} \mathrm{C}$. The range of concentrations of contaminants in the experimental solutions corresponded to the content of the same contaminants as in the actual wastewater of the agroindustrial complex: $C_{\text {start }}$ ammonium nitrogen - 20-70 mg/ $\mathrm{dm}^{3} ; C_{\text {start }}$ phosphates $20-100 \mathrm{mg} / \mathrm{dm}^{3}$.

The adsorption capacity of the sorbent (a) was determined by the following formula: 


$$
a=\frac{\mathrm{C}_{\text {start }}-\mathrm{C}_{\text {end }}}{m} V
$$

where: $C_{\text {start }}$ is the initial concentration of the pollutant in solution, $\mathrm{mg} / \mathrm{dm}^{3}$;

$C_{\text {end }}$ is the final concentration of the contaminant in solution, $\mathrm{mg} / \mathrm{dm}^{3}$;

$m$ is a fraction of the sorbent, $\mathrm{g}$;

$V$ is the volume of solution taken for the study, $\mathrm{dm}^{3}$.

\section{RESULTS AND DISCUSSION}

The isotherms of sorption corresponding to the ammonium ions and phosphates on the upland on lowland peat samples from aqueous solutions are presented in Figure 3 and 4.

As it can be seen from the presented research results (Fig. 3, 4), the Vereshchytsia-Yanovske deposit has the ability to remove the biogenic elements from the water. The structural intertwining of plant residues (Fig. 2-b), spatial and colloidal structures of peat, absorb a considerable amount of water and cause its adsorption properties. This is confirmed by the different moisture loss of lowland and upland peat samples established in the research process $-52.2-56.6 \%$ and $35.7-41 \%$ respectively.

The sorption properties of the lowland peat are higher than the lowland (lowland peat $\mathrm{pH}-5.08$, high -5.29 ) by 1.26 times for the ammonium ions and 1.59 times for phosphates. The adsorption capacity of the lowland peat to phosphate is 1.39 times higher than that of ammonium ions.

The experimental studies on the adsorption isotherms of ammonium ions and phosphates on natural peat were used to mathematically establish the isotherm equation. The most commonly used equilibrium models are Langmuir and Freundlich. The Langmuir model assumes adsorption on the surface of the sorbent of the monomolecular layer of the adsorbent, and the isotherm equation has the form [J. Warchol, 2012]:

$$
a=a_{\infty} \frac{\mathrm{b} \mathrm{c}}{1+\mathrm{bc}},
$$

where: $c$ is the concentration of ions in the liquid, which is equilibrium with the adsorption capacity a in the solid phase;

$a_{\infty}$ - maximum sorption capacity of peat; $b$ is the coefficient.

Equation (3) was represented as a linear function:

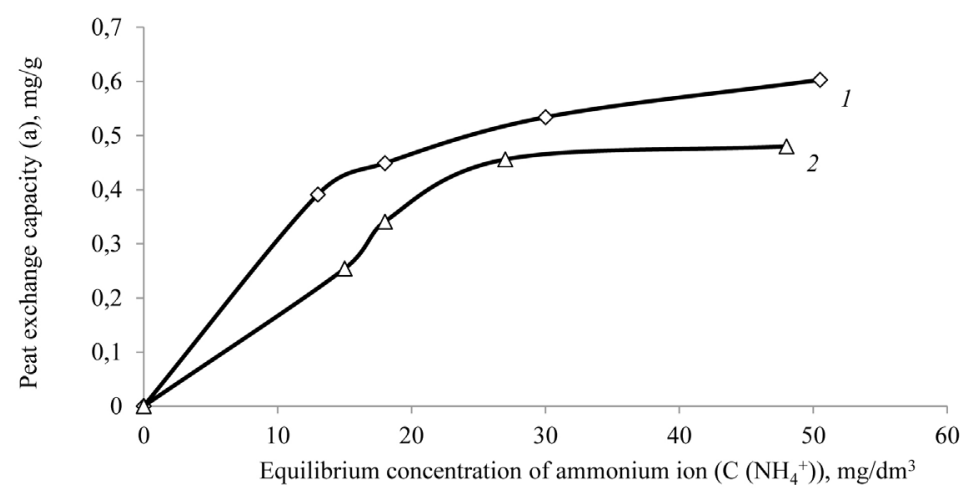

Fig. 3. Isotherm of sorption of the ammonium ions on the peat of Vereshchytsya-Yanovske deposit: 1 - lowland sample; 2 - upland sample

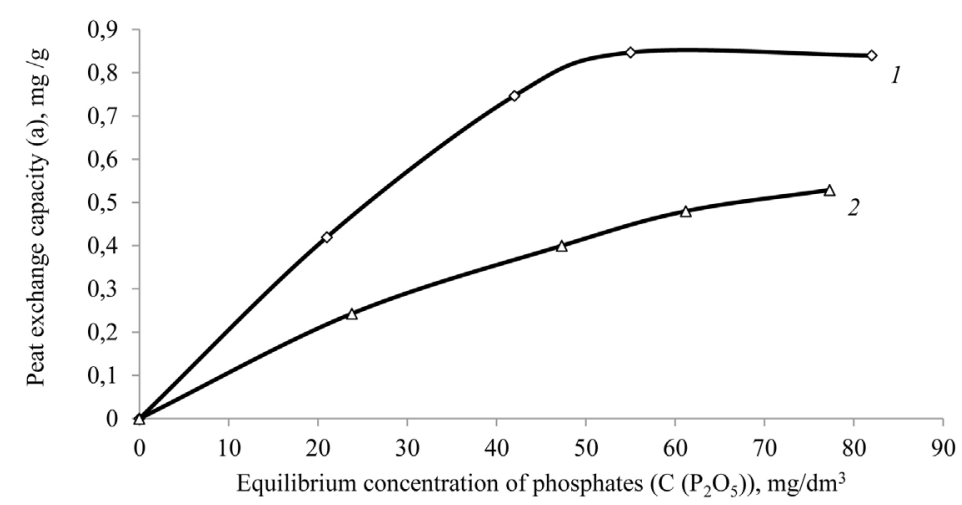

Fig. 4. Phosphate sorption isotherm on the Vereshchytsya-Yanovske peat field: 1 - lowland sample; 2 - upland one 


$$
\frac{\mathrm{c}}{a}=\frac{1}{a_{\infty} \mathrm{b}}+\frac{1}{a_{\infty}} \mathrm{c},
$$

According to which $1 / a_{\infty}$ represents the slope angle tangent and allows us to determine $a_{\infty}$. The coefficient $b$ is determined from the free term.

The Freundlich model describes the equilibrium relations by the following equation:

$$
a=b_{1} c^{1 / n} \text {, }
$$

where: $b_{1}$ and $n$ - coeeficients.

Equation (5) in linear form is:

$$
\log a=\log b_{1}+\frac{1}{n} \log c
$$

The degree of appropriation of linear equations to experimental data was estimated on the basis of the coefficient of determination $R^{2}$.

a)

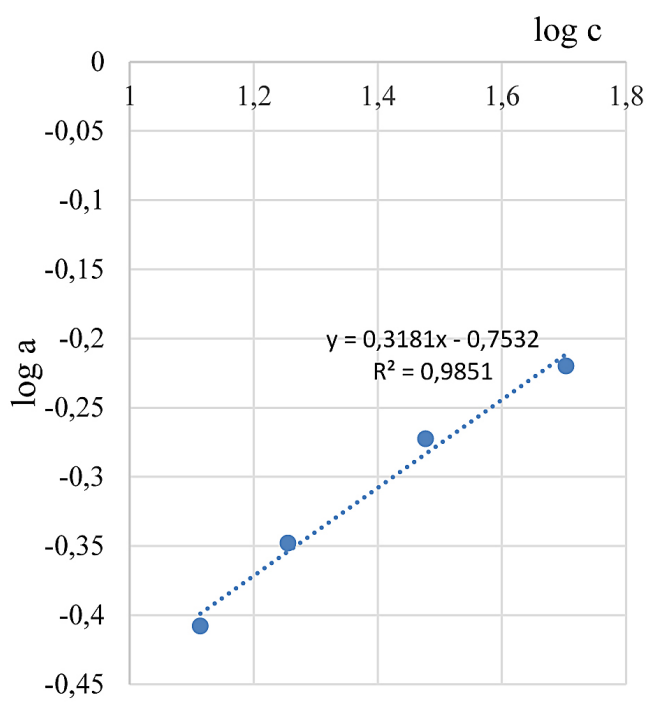

Fig. 5. Representation of the adsorption isotherms of the ammonium ions in a linear form for the lowland sample of the Vereshchytsya-Yanovske peat field: a) approximation by the Freundlich equation; b) approximation by the Langmuir equation

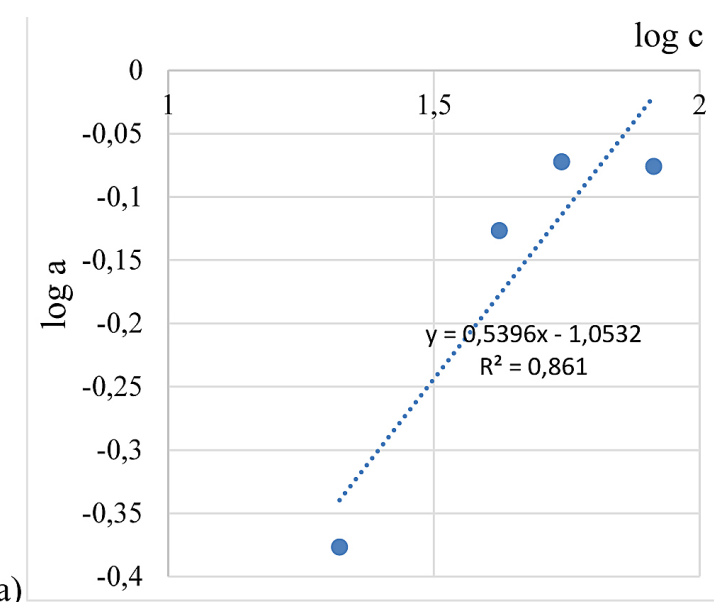

a)

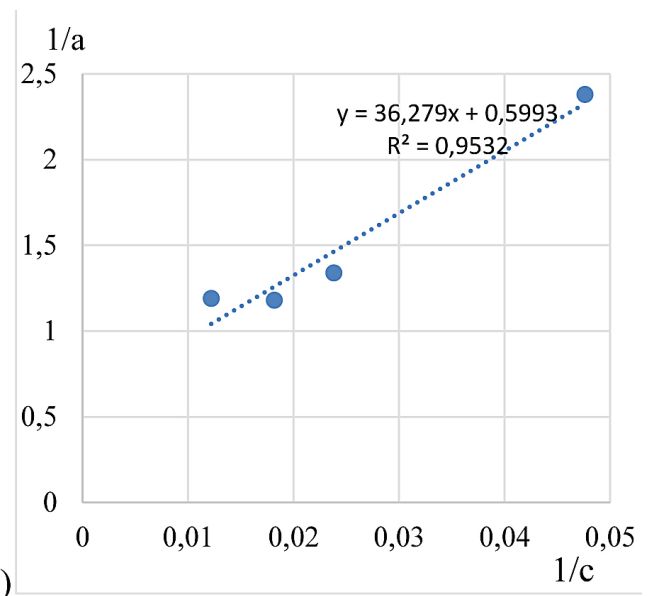

Fig. 6. Representation of the adsorption isotherms of the ammonium ions in a linear form for the VereshchitsaYanovske peat sample: a) approximation by the Freundlich equation; b) approximation by the Langmuir equation
In Figure 5 and 6, the adsorption isotherms of ammonium ions on the peat of the VereshchytsyaYanovske deposit for the lowland sample (Fig. 5) and the upland sample (Fig. 6) are presented.

According to the obtained linear approximations of the adsorption isotherms of ammonium ions for the samples of the lowland peat of the Vereshchytsya-Yanovske deposit, the following equations of isotherms with corresponding valobtained:

a) Freundlich equation:

$$
a=0.175 c^{1 / 3.144} ; R^{2}=0.9851 ;
$$

a) Langmuir equation:

$$
a=0.742 \frac{0.0855 c}{1+0.0855 c} ; R^{2}=1.0 \text {. }
$$

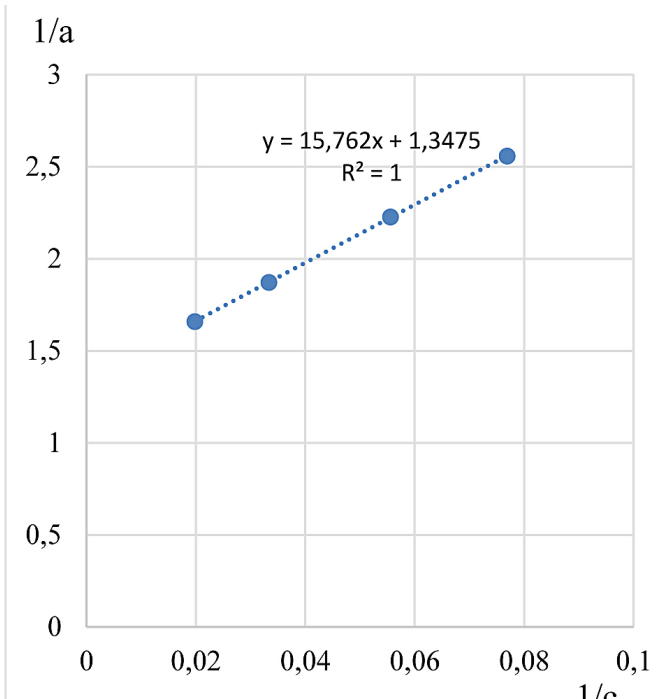

b) $1 / \mathrm{c}$ ues of the coefficient of determination $R^{2}$ were 
Equation of the adsorption isotherms with corresponding values of the deterministic coefficient $R^{2}$ for the upland sample of peat of the Vereshchitsa-Yanovske deposit:

a) Freundlich equation:

$$
a=0.0733 c^{1 / 1.968} ; R^{2}=0.7932 ;
$$

b) Langmuir equation:

$$
a=0.980 \frac{0.026 c}{1+0.026 c} ; R^{2}=0.8626 .
$$

In Figures 7 and 8 the isotherms of phosphate adsorption on the peat of the Vereshchytsya-Yanovske deposit for the lowland sample (Fig. 7) and the upland one (Fig. 8) are presented.

According to the obtained linear approximations of the phosphate adsorption isotherms for the lowland peat samples of the
Vereshchytsya-Yanovske deposit, the following isotherm equations with corresponding values of the coefficient of determination $R^{2}$ were obtained:

a) Freundlich equation:

$$
a=0.088 c^{1 / 1.853} ; R^{2}=0.861 ;
$$

b) Langmuir equation:

$$
a=1.668 \frac{0.0166 c}{1+0.0166 c} ; R^{2}=0.9532 .
$$

Equation of the adsorption isotherms with corresponding values of the deterministic coefficient $R^{2}$ for the upland peat sample of the Vereshchytsa-Yanovske peat field:

a) Freundlicha equation:

$$
a=0.0733 c^{1 / 1.916} ; R^{2}=0.9932 ;
$$

b) Langmuira equation:

$$
a=1,167 \frac{0.011 c}{1+0.011 c} ; R^{2}=0.9992 .
$$

a)

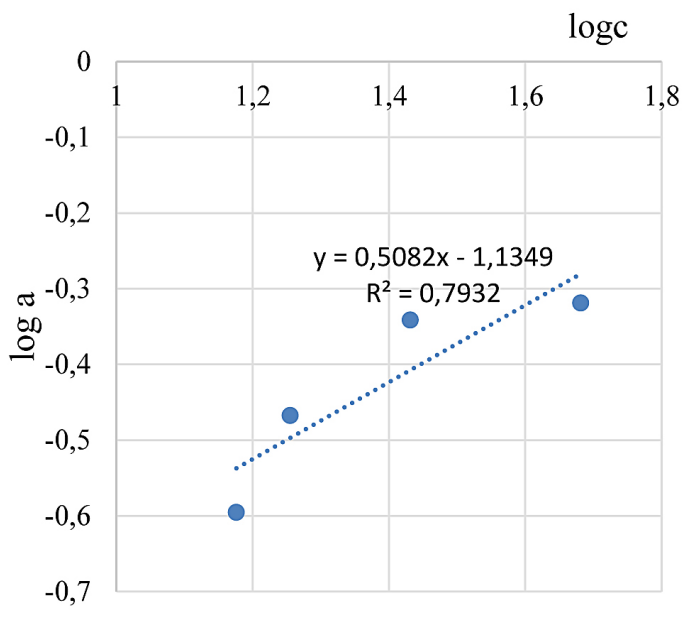

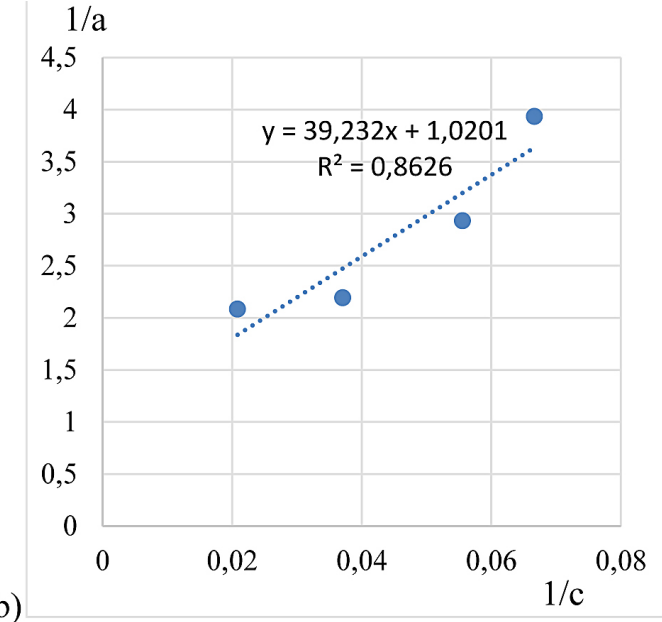

b)

Fig. 7. Representation of the phosphate adsorption isotherms in a linear form for the lowland peat sample of the Vereshchitsa-Yanovske deposit: a) approximation by the Freundlich equation; b) approximation by the Langmuir equation

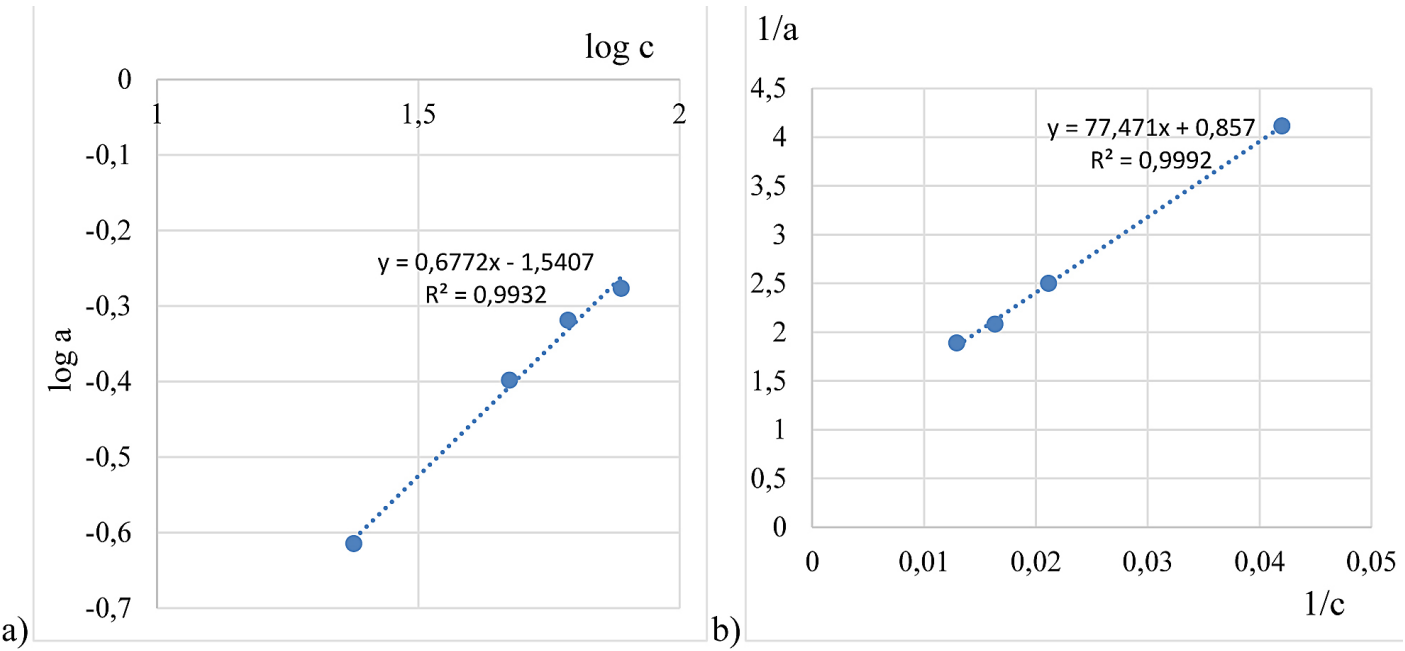

Fig. 8. Representation of the phosphate adsorption isotherms in a linear form for the Vereshchytsa-Yanovske peat deposit: a) approximation by the Freundlich equation; approximation by the Langmuir equation 


\section{CONCLUSIONS}

Peat can be used to treat wastewater from the ammonium ions and phosphates. The sorption capacity of the lowland peat samples of the studied

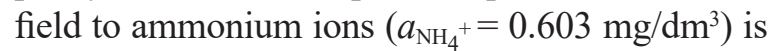
higher than the upland one $\left(a_{\mathrm{NH}_{4}{ }^{+}}=0.480 \mathrm{mg} / \mathrm{dm}^{3}\right)$. Similarly for phosphates: the sorption capacity of the lowland peat samples is $a_{\mathrm{P}_{2} \mathrm{O}_{5}}=0.840 \mathrm{mg} / \mathrm{dm}^{3}$ and the upland one is $a_{\mathrm{P}_{2} \mathrm{O}_{5}}=0.529 \mathrm{mg} / \mathrm{dm}^{3}$.

The structural entanglements of plant residues, much of which are in the lowland peat samples, as well as its spatial and colloidal structures, absorb a considerable amount of water and cause the adsorption properties of peat. The moisture loss of lowland and upland peat samples was established, reaching 52.2-56.6\% and $35.7-41 \%$, respectively.

Peat can purify both the water cations and anions. For the cationic form there may be ion exchange, since the ion-exchange properties of peat are due to the presence of a highly dispersed fraction - colloidal substances, represented mainly by the humic substances.

The models for describing Langmuir and Freundlich are proposed. According to the determination coefficient, in each case, the Langmuir equations describe the adsorption isotherms more adequately.

\section{REFERENCES}

1. Borkowski A., Rydelek P., Szala M. 2012. Characteristic of adsorption of azotetrazolate on organic soils (peat). Ecological Engineering, 29, 17-25 (in Polish).

2. Boroday V.P., Tertichna O.V., Cavan M.P. et al. 2014. Ecological assessment of the environment in poultry production areas. Ecology, 4(137), 22-25 (in Ukrainian).

3. Humnytskyy Y., Matsuska O. 2011. Statics and kinetics of ammonium nitrogen sorption on natural zeolite under periodic conditions. Chemistry and chemical technology, 5(1), 7-11.

4. Krasinko V.O., Teterina S.M., Skokun T.M. 2012. The ways of intensification of food productions wastewater treatment from ammonium and saponins. Economy. Ecology. Management: Coll. of Sci. Wk. Irpin, 1, 157-162 (in Ukrainian).

5. Kravchenko V.S. Bodnaruk T.S., Kravchenko Y.V., Kurilyuk M.S. 2009. Perspectives on peat usage for the treatment of highly concentrated industrial wastewater. Bulletin of the National University of
Water and Environmental Engineering, 3(47), 2, 250-257 (in Ukrainian).

6. Kushvaha J.P., Srivastav V.C., Deo Mall I. 2011. An Overview of Various Technologies for the Treatment of Dairy Wasterwaters. Critical Reviews in Food Science and Nutrition, 51, 442-452.

7. Malovanyy M., Petrushka K., Petrushka I. 2019. Improvement of Adsorption-Ion-Exchange Processes for Waste and Mine Water Purification. Chemistry and chemical technology, 13(3), 372-376.

8. Masliy I.V. 2015. Problems of livestock enterprises wastewater treatment. Bulletin of Sumy National Agrarian University. Series: Building, 10(19), 7577 (in Ukrainian).

9. Matsuska O.V., Paranyak R.P., Gumnitskii Y.M. 2010. Adsorption of wastewater components by natural sorbents. Journal of Water Chemistry and Technology, 32(4), 218-222.

10. Matsuska O.V., Tsizhovska M.V., Khapko D.M. 2019. Perspective ecological processes of agricultural sewage water treatment when using nontraditional sorbents. Scientific Messenger of Lviv National University of Veterinary Medicine and Biotechnologies. Series: Agricultural sciences, 21 (91), 54-59 (in Ukrainian).

11. Sabadash V., Gumnitsky J., Hyvlyud A. 2016. Mechanism of phosphates sorption by zeolites depending on degree of their substitution for potassium ions. Chemistry and chemical technology, 10(2), 235-240.

12. Sabliy L.A. 2013. Physico-chemical and biological treatment of highly concentrated wastewater. NUWEE, Rivne city (in Ukrainian).

13. Scharma D. 2014. Treatment of dairy waste water by electrocoagulation using aluminium electrodes and settling, filtration studies. International Jornal of Chem-Tech Research, 6(1), 591-599.

14. Stepa V.M. 2014. Reasoning of the algorithm of experimental-analytical researches of the modes of electrotechnical sewage treatment of agro-industrial objects with the purpose of building energyefficient control systems. Energy and Automation, 2, 61-71(in Ukrainian).

15. Timchuk I., Malovanyy M., Odnorih Z., Gadzhula T. 2013. Ecological and economic aspects of the use of natural sorbents in agro-technologies. Coll. International Scientific-Practical Conference «Socioecological Problems of Transition to Sustainable Development: Realities and Prospects of the 21st Century», NUBiP, Kherson, 76-78 (in Ukrainian).

16. Warchol J. 2012. Investigation and modeling of ion sorption equilibrium in a liquid-solid system. PAN, Lodz (in Polish).

17. Ye H., Zhand Y., Li H. et all. 2012. Investigation of separation of lactose from whey solution by nanofiltration process. Advanced Materials Research, 485, 352-356. 